\title{
ADOÇÃO INTERNACIONAL: VALOR E IMPORTÂNCIA DAS CONVENÇÕES INTERNACIONAIS VIGENTES NO BRASIL
}

\author{
Georgette Nacarato Nazo \\ Professora Doutora do Departamento de Direito Internacional da \\ Faculdade de Direito da Universidade de São Paulo
}

Resumo:

Este estudo se inicia observando que, além dos problemas existentes nas relações humanas entre aqueles que decidem adotar e os que são adotados, há outros problemas que envolvem o conflito internacional de leis.

Em seguida, a autora demonstra que, a nível nacional, somente com a vigência da Constituição brasileira de 1988 e do Estatuto da Criança e do Adolescente, de 1990, é que a questão da adoção da criança e do adolescente recebeu o tratamento que merece.

$\mathrm{Na}$ seqüência, o estudo demonstra que as convenções internacionais têm sido a solução encontrada pelos Estados soberanos para solucionar os conflitos internacionais de leis. Assim, aborda detalhadamente três Tratados Internacionais que colaboram para uma melhor administração da justiça e da tutela dos interesses e direitos das crianças e dos adolescentes. Estes Tratados também enfatizam a cooperação judiciária internacional: Convenção de Cooperação Judiciária en matéria civil, comercial, trabalhista e administrativa Brasil-França, Convenção Interamericana sobre conflitos de leis em matéria de adoção de menores, assinada em La Paz e a Convenção de Cooperação Internacional e Proteção de Crianças e Adolescentes em matéria de adoção internacional, concluída em Haia.

Tendo em vista que a defesa dos direitos das crianças e adolescentes é primordial, além das convenções interestatais de cooperação judiciária, as recomendações do Instituto de Direito Internacional (que visam uniformizar o enfoque de determinadas matérias) e as entidades internacionais de adoção receberam atenção especial pela autora.

Ao final, conclui que, se o ordenamento jurídico interno brasileiro for respeitado, a adoção internacional surge como opção real a ser considerada pelos Juizados da Infância e Adolescência a fim de que tais jovens possam ter seus direitos respeitados.

Abstract:

This study begins by observing that, besides the existing problems in the human relationship between those who decide to adopt and those who are adopted, there are other problems that involve international conflicts of laws.

Following, the author shows that, in the national level, only with the brazilian Constitution, of 1988, and the Act of the Child and Adolescent of 
1990, the adoption of children and adolescents received the treatment it truly deserves.

Next, the study shows that the international treaties are the solution found by the sovereign States in order to solve the international conflict of laws. So, it stands out with details three International Treaties that corroborate for a better administration and protection of concerns and rights of the children and adolescents. These Treaties also emphasize the international juridical cooperation: Treaty of Judiciary Cooperation in Civil, Commercial, Labor and Administrative subjects Brazil-France, Inter - American Treaty of Conflicts of Laws Concerning Adoptions of Minors, signed in La Paz and the International Treaty of Cooperation and Protection of Children and Adolescents Referring to International Adoption, signed in Haia.

On account of the fact that the defense of children and adolescents rights is primordial, besides the international treaties of judiciary cooperation, the recommendations from the International Law Institute (intending to equalize the interpretation of certain determined subjects) and the international organizations of adoption received special attention by the author.

At last, concluding that, if the brazilian internal corpus of laws is respected, the international adoption is a real option to be considered by the Brazilian Courts of Childhood and Adolescence so those young people shall have their rights respected.

Unitermos: adoção nacional e adoção internacional; legitimação adotiva; conflitos da adoção internacional; proteção na adoção internacional.

Sumário:

1. Preliminares ao seu estudo.

2. O instituto da adoção e a Constituição Federal de 1988.

3. Textos internacionais e convenções:

3.1. Convenção de cooperação judiciária em matéria civil, comercial, trabalhista e administrativa Brasil-França.

3.2. Convenção interamericana sobre conflitos de leis em matéria de adoção de menores, votada em La Paz (Bolívia), aos 24.05.1984.

3.3. Convenção de cooperação internacional e proteção de crianças e adolescentes em matéria de adoção internacional, concluída em Haia, aos 29.05.1993, em vigor no Brasil pelo Decreto-legislativo n. 63, de 19.04.1995.

4. As conexões pessoais e o instituto de direito internacional UNIDROIT. 
5. Outros importantes aspectos da convenção sobre cooperação internacional e proteção de crianças e adolescentes em matéria de adoção internacional entidades dedicadas à adoção.

6. Conclusão.

\section{Preliminares ao seu estudo.}

O instituto da adoção de menores e adolescentes abandonados é dos mais generosos e benéficos, tanto no plano nacional, quanto no internacional.

Matéria contraditória que, por vezes, se torna complicada em razão de políticas legislativas descoordenadas em diversos ordenamentos jurídicos, a despeito da tendência generalizada nestes últimos tempos, em se manter um maior controle, visando salvaguardar o bem-estar dos menores, evitando-se o tráfego ilícito e a venda indiscriminada dos mesmos, transfronteiras, como é normal na Holanda.

Apesar disso, em se tratando de adoções nacionais, ou seja entre adotantes e menores de um mesmo país, as soluções são dadas na conformidade de disposições legislativas próprias, inspiradas na melhor doutrina e na prática jurisprudencial dos direitos internos, quando a aceitam, quer de modo pleno, quer simples, ou em outras formas aí previstas.

Todavia, em se tratando de adoções transfronteiras, objeto específico desta exposição, é preciso se levar em conta uma série de fatores ligados à pessoa humana e que podem obstar, complicar e empecer o generoso gesto daqueles que pretendem acolher em seu lar, menores estrangeiros, abandonados por seus genitores, carentes, desnutridos e, por vezes, portadores de deficiências físicas e/ou mentais.

É seara polêmica, onde se mesclam: caridade, amor, família, ao lado de outros fatores como: poder, egoísmo, dinheiro, falsidades e nacionalismos sentimentalóides.

Sob o ângulo das divergências legislativas internas dos países, bem como do instituto da adoção, até recentemente, ser desconhecido por alguns ordenamentos jurídicos é que surgem conflitos espaciais de leis.

* Palestra proferida aos 13.05.97 no Salão Nobre da FDUSP, no curso Direitu de Família à luz. da Nova Constituição brasileira de 1988 (Extensão Universitária) coordenado pelo professor Álvaro Villaça Azevedo. 
De um modo geral, a base do exame é saber qual a lei aplicável, pois na adoção de estrangeiros, ou por estrangeiros há dois ângulos a serem considerados:

O primeiro é que o adotado se vincula ao adotante, desligando-se da família de origem; o exame da lei aplicável dependerá das condições dessa adoção e se torna o problema fundamental que estabelece a área conflitual existente entre dois direitos internos: o do adotante e o do adotando (ou candidato à adoção por estrangeiro).

O segundo aspecto é que a adoção poderá ser concedida por uma decisão (judicial ou administrativa) e, portanto, estabelece um novo status para o adotado e dependerá da lex fori ou da lex auctoritatis. Logo, a competência dessa autoridade é o fulcro da questão, quando se tratar de adoções internacionais, podendo, então, surgir não um problema conflitual de leis, mas de autoridades.

Melhor explicando: 1. a adoção apresenta um elemento estrangeiro; portanto, característica de Direito Internacional privado; 2. a adoção feita no estrangeiro, atendendo às exigências da lei local e cujos efeitos devem produzir-se extraterritorialmente, mediante o reconhecimento do ato concessivo dessa adoção; é a questão da eficácia da decisão proferida aliundi, pelo direito interno de outro país. Também, aqui, a matéria envolvendo processo internacional é âmbito próprio ao Direito Internacional Privado.

É bem verdade que, em situações tais, a tendência da comunidade internacional tem sido a de solucioná-las por via de convenções interestatais, buscando harmonizar e, se possível, uniformizar o tratamento de determinados institutos, viabilizando os relacionamentos transfronteiras, quer em nível regional, quer sub-regional, ou com maior cooperação, em nível mundial.

No que tange às adoções internacionais de menores e adolescentes veremos que, sem embargo das dificuldades acima referidas, ou seja: disposições legislativas descoordenadas, de longa data, nos direitos internos, aliadas a desconhecimento ou rejeição do instituto, somente em época bem recente, se chegou a resultados positivos, em foros multilaterais, no disciplinamento da matéria.

2. O instituto da adoção e a Constituição Federal de 1988.

Desde a mais remota antigüidade era conhecida esta figura jurídica, encontrando-se regulamentada no Código de Hamurabi, em 2283 a.C. Tanto os 
egípcios, quanto os gregos se serviram do instituto, sendo que foi, através dos romanos, que teve penetração na cultura ocidental. Os romanos praticaram-na para manter o culto doméstico dos sacra privata e como perpetuação de seu próprio nome, na ausência de filhos. Apresentava-se em duas espécies: para os alieni juris, constituindo-se em adoção propriamente dita, no primeiro caso, e arrogação, também chamada perfilhação de adultos sem pais.

Modernamente, a arrogação subsistiu para menores, no Código de Família, da Bolívia, de 23.08.1972 (Decr. legislativo n. 10.426) em seu art. 216 n. 3. A perfilhação coincide com a affiliazione do Direito italiano, onde o menor é acolhido por uma família como seu afilhado, podendo tomar o nome do adotante ou perfilhante que passa a exercer as funções inerentes ao pátrio poder. Todavia, não confere ao menor um verdadeiro status, tanto assim que, em ocorrendo casamento entre pessoas ligadas pela affiliazione, esta se extingue de pleno direito.

Instituto de ordem pública tem como característica, na adoção plena, a transferência do pátrio poder dos pais de sangue para os adotantes, mediante um ato solene, voluntário, sinalagmático e, em princípio, irrevogável. Estabelece-se entre adotante e adotado um vínculo fictício de paternidade e filiação legítimos, criando direitos e deveres recíprocos, com o estabelecimento do parentesco civil.

Tais foram as noções básicas incorporadas ao Direito pátrio, que assimilou o instituto desde as Ordenações, passando ao Códiøro Civil, de 1916, na aceitação das disposições do Código Bustamante, 1929, ao Código de Menores de 1942, às legislações que reestruturaram e ampliaram a adoção em 1957 (Lei n. 3.133 de 08.05) e em 1975, com a legitimação adotiva (Lei n. 4.655 de 02.06).

No entanto, negligenciou o Brasil, em todas as Constituições Federais promulgadas (ao todo foram 7), até o ad́vento da Carta Magna, de 1988, em nelas inserir princípios dos direitos das crianças, mesmo tendo sido signatário da Declaração Universal dos Direitos da Criança, de 20.11.1959, firmada na ONU, que reafirmou a proteção especial à infância, enunciada em Genebra, em 1924, pelas conseqüências desastrosas da Primeira Grande Guerra.

Em boa-hora, graças a inúmeras reivindicações de entidades privadas e setores da administração pública, a Emenda Popular: "Criança, Prioridade Nacional", encontrou eco na elaboração da Constituição Federal de 1988. Com efeito, os graves problemas sócio-econômicos do País, semelhantes aos que se verificavam e ainda hoje subsistem no Continente Centro-Sul-Americano, estavam a 
merecer uma tomada de posição que resgatasse os menores e os adolescentes como cidadãos, com direito a uma tutela e defesa especial.

Também, em boa-hora, o Brasil que, de há muito precisava rever e repensar o instituto da adoção de menores e adolescentes, fê-lo de forma candente no Capítulo VII - (arts. 226/230) da atual Constituição Federal, estabelecendo os princípios básicos da família, da criança, do adolescente e do idoso, indo além do enunciado geral do art. $5^{\circ}$ (Capítulo I): Dos Direitos e Deveres Individuais $e$ Coletivos. Destarte, adoção nacional e transnacional prevista no $\S 5^{\circ}$ do art. 227 , realizam-se na forma da lei, assistidas pelo Ministério Público e o $\S 6^{\circ}$ equiparou os direitos e qualificações dos filhos, havidos ou-não da relação de casamento, ou por adoção, tornando proibidas quaisquer designações discriminatórias relativas à filiação.

Com a promulgação da Lei n. 8.069 de 13.07.1990, retificada sua publicação em 27.09.1990: o Estatuto da Criança e do Adolescente ECA, ficaram disciplinados os seus direitos e deveres, com proteção mais incisiva do que até então havia no Direito pátrio.

A matéria contemplada nos arts. 39 a 52, entre outras, abraça a adoção plena tanto no âmbito interno, quanto por estrangeiros residentes fora do País.

Antes de examinar as condições indispensáveis à efetivação da adoção plena por estrangeiros, entendo necessário relembrar, aqui, textos internacionais que serviram de esteio e embasamento ao legislador brasileiro e inspiraram a melhor doutrina no que tange à proteção do cidadão, de modo geral, e do menor e do adolescente, apesar de terem sido incorporados ao direito interno, alguns deles, somente na década de 90 .

De outra parte, o tema dos menores, da juventude e das adoções transnacionais, foi objeto de convenções internacionais a que o Brasil aderiu e já vigoram para o Direito pátrio. 
3. Textos internacionais e convenções:

Já me referi à preocupação com a proteção especial à infância, enunciada em 1924, em Genebra, à época da Liga das Nações, após a Primeira Grande Guerra, com fins humanitários.

Sob a égide da ONU, portanto depois da Segunda Guerra Mundial, com a Declaração dos Direitos do Homem, em 1948, alvitrou-se votar um texto mais específico direcionado às crianças. Foi a $1^{\mathrm{a}}$ Declaração dos Direitos da Criança, 1959.

Seguiram-se os Pactos Internacionais relativos aos Direitos Civis e Políticos e aos Direitos Econômicos, Sociais e Culturais, votados pela A.G., a 16.12.66, que entraram em vigor, internacionalmente, em 1976. O Brasil promulgouos, respectivamente, em 06.12.1992 e 06.07.1992, Decretos ns. 592 e 591. Nesses dois Pactos encontram-se disposições relativas à família e ao menor, nos arts. 23 e 24 do Pacto de Direito Civis e Políticos e no art. 10 do Pacto de Direitos Econômicos Sociais e Culturais.

Para as Américas, além da Declaração de Direitos e Garantias do Homem, promulgada pouco antes da Declaração Universal da ONU, em 1948, o Brasil - que já incorporara o Código Bustamante de Direito Internacional Privado, em 1929, onde a matéria da adoção vem regulada nos arts. 73 a 77 como integrante da Organização dos Estados Americanos, firmou a Convenção Americana sobre Direitos Humanos, aprovada na Conferência de San José da Costa Rica, em 1969, e que só foi publicada no País, em setembro de 1992, pelo Decreto n. 678.

Nesta Convenção, além dos direitos fundamentais da pessoa humana, os direitos da criança e sua proteção, encontram-se esculpidos no art. 19.

Com estes instrumentos, faz-se importante lembrar, aqui, Resoluções da A.G. da ONU que inspiraram a Convenção relativa aos Direitos da Criança em 20.11.1989, assinada pelo Governo Brasileiro, em 26.01.1990, e aprovada pelo Decreto-legislativo de n. 28 aos 18.09.1990. Refiro-me às Resoluções n. 3.318 (XXIX) de 14.12.74, quando se fez a Declaração sobre a Proteção das Mulheres e das Crianças em períodos de guerra e urgência; Resolução n. 40/33 de 29.11.1985, que incorporou as Regras Mínimas de Beijing para administração da justiça aos menores e adolescentes; Resolução n. 41/85 de 03.12.1986, com a Declaração sobre Princípios Sociais e Jurídicos aplicáveis à proteção e ao bem-estar dos menores, 
visando sobretudo, as práticas em matéria de adoção e colocação em lares substitutos, nos planos nacional e internacional.

Na prática, o Estatuto da Criança e do Adolescente ECA (Lei n. 8.069 de 13.07.1990) constituiu-se num reflexo das iniciativas internacionais de proteção ao menor e à juventude, apesar do exagerado apego nacionalista quanto ao tema das adoções por estrangeiros em solo pátrio. Alie-se, a isto, a negativa de tutela e de guarda aos estrangeiros que reunam condições para bem-assistir e zelar por um adolescente brasileiro, mesmo que não pretendam realizar adoção plena. Quantas crianças órfãs ou abandonadas poderiam desfrutar de melhor nível de vida, dentro de um lar digno, ainda que fora de nossas fronteiras?

Não se exauriram, com a promulgação do ECA, as transformações internas para melhor administração da justiça e da tutela de interesses e direitos do menor, tanto em âmbito regional, quanto de tendência universal. Firmaram-se Convenções Internacionais, sendo certo que, uma delas, anterior ao Estatuto da Criança e do Adolescente e outras duas, posteriores, adiante mencionadas, obedecendo à ordem cronológica das mesmas.

3.1. Convenção de cooperação judiciária em matéria civil, comercial, trabalhista e administrativa Brasil-França.

Em janeiro de 1981, Brasil e França firmaram esta Convenção em Paris que entrou em vigor, aos 29.04.1985, por força do Decreto n. 91.207 e que permite ao advogado de ambos os países, devidamente inscritos em suas respectivas entidades profissionais, apresentar-se na congênere do outro país, para o exercício da advocacia, dando atendimento a mandato outorgado por seus constituintes.

No que diz respeito aos pedidos de reconhecimento e execução de sentenças judiciais relativas à guarda de menores, ao direito de visitá-los e receb $\hat{e}$ los e às obrigações alimentares, a Convenção cuida da matéria, no art. 26 ( $1^{\mathrm{a}}$ parte), esclarecendo que devem ser encaminhados por intermédio das Autoridades Centrais, ou seja: os Ministérios designados, Justiça e/ou Negócios Externos e estas autoridades é que devem se dirigir às autoridades competentes de cada país. Note-se que tal Convenção bilateral não-aborda os casos de adoções por estrangeiros e/ou de estrangeiros, restringindo-se à guarda, direitos de visita e alimentos.

Tanto no regime do revogado Código de Menores, com adoção simples do art. 20, quanto no atual do ECA, as diferenças legislativas brasileiras face 
ao art. 343 e ss. do Código Civil francês vinham criando embaraços às adoções transnacionais, não-só quanto aos limites de idade, como nas condições para se viabilizarem, pois a França admite os dois modos de adoção: simples e plena; e, mesmo nesta última, dificilmente autorizava a aquisição de nacionalidade francesa ao adotado. Que se dizer nas adoções simples, que vigoraram para menores em situação irregular, conforme art. 20 do nosso Código revogado?

Os franceses, desejosos de adotar, burlavam esta última dificuldade, realizando um tráfico vergonhoso e ilícito de crianças da América Latina (Peru, Brasil, Chile, El Salvador, Costa Rica) e Ásia, sem controle das autoridades locais.

$\mathrm{E}$, no que tange às condições para a adoção e limites de idade, enquanto a lei francesa exigia ter um dos cônjuges mais de 35 anos, estar casado há mais de cinco e não possuir filhos, só poderia adotar menores de quinze anos. Conseqüentemente, a diversidade legislativa obriga o juiz brasileiro para concretizar a adoção e na salvaguarda dos interesses do adotando brasileiro, a ter presente a legislação francesa e aplicá-la, por exceção, atendendo as nossas regras instrumentais de Direito Internacional Privado, de sorte a que o menor possa adentrar o território francês.

É sempre aconselhável que conste, na sentença de adoção, que o Consulado da França ao emitir o passaporte do adotado só o faça mediante a comprovação pelos adotantes do registro do ato de adoção no Livret de Famille do próprio Consulado e que será encaminhado ao Serviço Central de Estado Civil do Ministério das Relações Exteriores, francês. Semelhante providência casa-se com o disposto no art. 23 da Convenção, porquanto ... "As sentenças em matéria de estado das pessoas e que façam coisa julgada poderão, todavia, ser inscritas sem homologação no registro civil, se a isso não se opuser o direito do Estado onde se situar tal registro.

Deve-se fazer, aqui, uma outra observação, quanto à $2^{\mathrm{a}}$ parte do art. 26 da Convenção, que trata do deslocamento ilícito ou de retenção abusiva de menores e que tem muito a ver com casos de seqüestro. É doloroso dizer-se que, na primeira oportunidade que se teve para aplicar esta Convenção, não houve, efetivamente, qualquer cooperação por parte da França, há mais ou menos uns dez anos. Refiro-me ao seqüestro de um garoto, no Rio de Janeiro, filho de brasileira e francês, perpetrado pelo pai que o levou para a França. Tomou, a genitora, as providências judiciais junto a $1^{\mathrm{a}}$ Vara da Família. Foram expedidas rogatórias, totalmente ignoradas em França. 
Numa segunda etapa, a brasileira iniciou as providências em França, obtendo decisões favoráveis; contudo, tais foram as exigências impostas pelos tribunais franceses à brasileira, que se tornou impossível cumprí-las e executá-las, apesar da interferência da Ordem dos Advogados francesa, na pessoa de seu então presidente (caso: M. Célia Vargas x Raymond Rozner - RJ).

Este caso, bem ilustra o descompasso entre legislações e, como é curial, a desigualdade de tratamento que os tribunais franceses dão ao seu nacional e ao estrangeiro. Quero crer que o legislador brasileiro, ao elaborar o ECA, perfilhou a ala da doutrina adversa à adoção por estrangeiros, eivando-a de uma burocracia e lentidão que visam dificultá-la. Haja vista, a exigência de um estágio preliminar de aproximação com o adotável que, se psicologicamente, é plenamente justificável, não deve se estender por longo período, com os corolários daí decorrentes. Explico: a estrangeiro deve permanecer no País, sem exercer atividade remunerada, o que fere seu direito fundamental ao trabalho; enquanto não transita em julgado a decisão, o tempo corre e o estrangeiro fica desocupado, arcando com os ônus de hospedagem, alimentação, etc; o efeito suspensivo da decisão, agrava, ainda mais, a situação do adotante estrangeiro, pois, além dessas despesas, não pode deixar o País, nem providenciar os registros do menor e a obtenção do respectivo passaperte. Onde fica a celeridade na solução de um caso que se baseia no amor e na fraternidade, sem preconceitos?

3.2. Convenção interamericana sobre conflitos de leis em matéria de adoção de menores, votada em La Paz (Bolívia), aos 24.05.1984.

Pela circunstância de o Código Bustamante de Direito Internacional Privado, votado em Havana, em 1928 - promulgado no Brasil, pelo Decreto n. 18.871 de 13.08.1929, já não mais atender à realidade intercontinental americana, as Conferências Interamericanas de Direito Internacional Privado, as chamadas CIDIPs vêm examinando projetos de convenções em diversas matérias, buscando, nestas duas últimas décadas, obter harmonização ou uniformidade de tratamento, sendo que várias já se acham em vigor no Brasil.

No que se refere à adoção internacional e aos seus eventuais conflitos de leis tive oportunidade de exarar parecer para o Departamento de Direito Internacional, em novembro de 1990, publicado na Revista Trimestral de Jurisprudência dos Estados - v. 97, pp. 87 a 92. Trata-se de Convenção celebrada 
em La Paz, aos 24.05.84, aprovada pelo Decr. Legislativo n. 60, de 19.06.1996, com 29 artigos e que se aplica às adoções plenas, legitimação adotiva e formas afins que equiparem o adotado à condição de filho legítimo, tendo as partes domicílios e/ou residência habitual em Estados-Partes diferentes, no âmbito da OEA. É, portanto, Convenção regional, envolvendo maior número de países, com similitudes de problemas sócio-econômicos e um contingente de menores carentes, abandonados, muitas vezes largados à própria sorte, outras vezes, recolhidos por instituições públicas ou privadas.

Ressaltem-se dois aspectos importantes: o primeiro, de que países hispânicos que não incorporaram o Código Bustamante, ou lhe apuzeram "reservas" ou "ressalvas" como Uruguai, Paraguai, Colômbia, Costa Rica, Salvador, República Dominicana, Equador, Chile e Argentina, além do México e dos EUA, têm participado das CIDIPs, acolhendo as novas convenções interamericanas;' o segundo é que países, que ignoravam o instituto da adoção, introduziram modificações no seu direito interno, admitindo as adoções internacionais, como se deu no Chile, com a Lei n. 18.703, de 26.04.88, revogando lei anterior que só admitia a legitimação adotiva. O mesmo ocorreu no Equador, introduzindo modificações no Código de Menores, estabelecendo um regulamento próprio às adoções de menores, tanto nacional, quanto internacional.

Resta claro, pois, que a Convenção Interamericana sobre Conflitos de Leis em Matéria de Adoção de Menores deve ser considerada, nos casos de adoções transnacionais entre os países americanos que a ela se vincularam. Caberá, ao Juízo brasileiro, na hipótese de um estrangeiro com domicílio em outro Estado-Parte nesta Convenção pretender adotar crianças brasileiras, exigir o cumprimento integral dos requisitos previstos para a adoção plena, sempre no atendimento dos interesses da criança e na conformidade do ECA, ficando, assim, atendidos os arts. $3^{\circ}, 4^{\circ}, 12$ a 19 da Convenção.

Já, em se tratando de caso inverso, adoção feita em país estrangeiro, Parte na Convenção, aplica-se o art. $5^{\circ}$ desta que proclama o reconhecimento dos efeitos de pleno direito nos demais Estados-Partes. Reporto-me aos comentários de meu parecer retromencionado.

1. Os três paises: Argentina, Paraguai e Uruguai que são copartícipes do Brasil no Mercosul, nãoaceitaram o Código Bustamante, residindo, ai, a primeira dificuldade de harmonização de normas jurídicas entre eles. 
3.3. Convenção de cooperação internacional e proteção de crianças e adolescentes em matéria de adoção internacional, concluída em Haia, aos 29.05.1993, em vigor no Brasil pelo decreto legislativo n. 63, de 19.04.1995.

Se a Convenção Interamericana de La Paz foi benéfica aos países que a subscreveram, resultou muito mais clara a matéria das adoções transnacionais, com esta Convenção de Haia, em seus 48 artigos.

Realmente, todo o problema de conflitos de leis dos ordenamentos internos dos países ficou solucionado ao se estabelecer como elemento de conexão pessoal para adotante(s) e adotando(s) a lei da residência habitual em seus respectivos países para dizer da lei aplicável às condições e requisitos a serem atendidos para a adoção internacional, que estabeleça vínculo de filiação. Ou seja: os arts. $4^{\circ}$ e $5^{\circ}$ em diversos ítens, ponderam que as autoridades competentes do Estado de origem do adotando é que determinam que o menor até dezoito anos é adotável, depois de verificar a impossibilidade da adoção em seu próprio Estado; que assegurará uma adoção em seu próprio Estado; que assegurará uma adoção internacional, atendidas as exigências quanto ao consentimento da criança e, conforme o caso, sua oitiva, assegurando-se o bem-estar do adotando. Quanto aos requisitos dos adotantes, as autoridades do Estado de acolhida do menor é que devem assegurar a possibilidade dessa adoção e de que a criança será autorizada a entrar e residir permanentemente no Estado de acolhida.

Em seu art. 23, ao cuidar do reconhecimento e efeitos de uma adoção concedida por autoridade competente do Estado de origem, afirma que será reconhecida de pleno direito pelos demais Estados. Vejo, nesta expressão: reconhecimento de pleno direito da decisão estrangeira, a viabilidade de prescindirem de homologação pelo Estado de acolhida, como uma hermenêutica a valorizar o uso dos dispositivos da Convenção e implementar maior cooperação judiciária entre Estados, qualificando o julgado alienígena como direito e não como um fato estranho, tal como, durante largo tempo, tem sido entendido por alguns jusinternacionalistas.

Encontro apoio, neste ponto de vista, na recente reforma do sistema italiano de Direito Internacional privado ao editar a Lei n. 218, de 31.05.1995, que determina o domínio de sua jurisdição, os critérios para individuação do direito aplicável e o disciplinamento da eficácia das sentenças e atos estrangeiros. Explico, um pouco mais, alguns aspectos dessa nova lei italiana que entrou parcialmente em vigor em 01.09.1995, com ab-rogação de normas incompatíveis, tanto da lei geral 
precedente ao código civil, quanto disposições do mesmo código civil e de processo civil; as demais disposições da nova lei passaram a ter vigência em 01.06.1996, ou seja, as pertinentes ao Título IV sobre a eficácia dos julgados e atos estrangeiros, que introduziu, no ordenamento jurídico, o princípio da eficácia automática do julgado estrangeiro, nos termos dos arts. 64-66 que se acham conectados, expressamente, ao art. 41 (reconhecimento de decisões estrangeiras em matéria de adoção) do Título III sobre o direito aplicável a adoção (Capítulo V - arts. 38 a 41).

A meu ver, não-só pelas inovações trazidas ao sistema jurídico italiano que, confessadamente, a doutrina e a jurisprudência percebiam a inadequação das suas normas de Direito Internacional Privado até então vigentes à atual condição da vida jurídica internacional, bem como a adesão a diversas convenções internacionais, bi ou plurilaterais, tornavam obsoletas as normas de conflito, face a algumas modificações do próprio direito comum, outro motivo inspirou-me a trazer, aqui, o aporte dessa legislação recente. Refiro-me à circunstância evidenciada nos tribunais brasileiros do ponderável número de adotantes italianos marcarem presença, no desejo de adotarem crianças, sem qualquer laivo de exigências ou discriminações.

Com efeito, o princípio da eficácia automática do julgado alienígena, conforme a nova sistemática italiana do Título IV da Lei n. 218/95, que mereceria análise mais profunda à boa-formação de qualquer jusinternacionalista, mas que extravasaria o âmbito desta exposição, obriga-me a dizer, aqui, o essencial. A decisão estrangeira, de per si, explica seus próprios efeitos automáticos, vez que transitou em julgado no ordenamento de origem e no respeito à ordem pública processual, tem idênticos efeitos na Itália, prescindindo de delibação. Nos sete itens do art. 64 vêem elencados os fundamentos para que se verifique a eficácia automática da decisão aliundi, sendo certo que a melhor doutrina aconselha e induz o juiz italiano ao uso cauto e parcimonioso da exceção de ordem pública obstativa à eficácia.

Semelhante princípio há algum tempo já vinha sendo praticado na Itália, em conseqüência de Convenções, bi ou plurilaterais, por ela aceitas, especialmente a de Bruxelas (1968), modificada pelas de Luxemburgo (1978 e 1982) e de Donistia (1989) e a de Lugano (1988), em qualquer matéria, quando não previsto, nas Convenções, o procedimento específico de exequatur a ser seguido.

Já, no que tange às adoções, a Jurisdição italiana interna restou expressa no art. 40 da Lei n. $218 / 95$ e quanto ao reconhecimento de decisões estrangeiras, no art. 41 que se reporta aos arts. 64-66. É certo, porém, que, em sua 
parte final, o art. 41 afirma subsistirem "as disposições da lei especial em matéria de adoção". Trata-se da Lei n. 184, de 04.05.1983 que, desde então, regulamentou a afiliação pré-adotiva, a tutela, a legitimação adotiva e as adoções, sendo competentes os Tribunais de Menores para o exame dessas questões. E, em se tratando de decisões estrangeiras, esses Tribunais sempre tiveram o ato estrangeiro como um pressuposto para emanação do decreto interno e conseqüente autorização para registro civil próprio. Não se fazia uma delibação técnica, porém, imprópria e residual, que corresponde à declaração de eficácia do julgado externo; e, nos casos particulares de adoção de menores estrangeiros que não tivessem caráter legitimante, a competência é das Cortes de Apelação.

Com o advento da nova lei de Direito Internacional Privado n. 218/95, especialmente esta $2^{\mathrm{a}}$ parte do art. 41 , vincula-se às outras figuras jurídicas referidas na lei interna de n. 184/83, em seus arts. 32 e 33 e as adoções internacionais são reconhecidas, automaticamente, segundo a regra comum do art. 64, com a ressalva da aplicação de normas convencionais, eventualmente mais favoráveis a esse reconhecimento. ${ }^{2}$

Dessume-se, então, que a incorporação pelo Direito italiano da Convenção de Haia de 1993, visando a proteção de crianças e adolescentes em matéria de adoção internacional e diante das novas normas de Direito Internacional Privado já em vigor no país, trarão eficiente cooperação judiciária internacional nas adoções realizadas conforme a Convenção, com a efetividade automática do julgado no Estado de origem do adotando, no Estado de sua acolhida.

2. Os arts. 65 e 66 da Lei n. $218 / 95$ mencionados no art. 41 prendem-se a decisões atinentes à capacidade das pessoas, relações de família e direitos da personalidade ou decisões graciosas estrangeiras. $\mathrm{O}$ reconhecimento, sem recurso a qualquer processo, também é automático, respeitada a ordem pública.

Recomenda-se a consulta à Rivista di Diritto Internazionale Privato e Processuale, ano XXXI n. 04 - out/dez, 1995. O fascículo traz os comentários dos melhores especialistas em cada artigo da lei de reforma do Direito Internacional Privado italiano. 


\section{As conexões pessoais e o instituto de direito internacional-UNIDROIT}

Faço, agora, uma outra explicação indispensável àqueles pouco afeitos às conexões pessoais de que se ocupa o Direito Internacional Privado.

Desde o início desta exposição, revelei existirem diferenças legislativas nos ordenamentos jurídicos dos diversos Estados da comunidade internacional. Muitas vezes, num mesmo país, há unidades territoriais autônomas a gerar conflitos interlocais de legislações, ou interestaduais como ocorre, por exemplo, nos EUA ou intercantonais, como na Suíça. Além desta dificuldade, as legislações também variam quanto ao elemento de conexão pessoal, acolhendo uns: a nacionalidade, outros: o domicílio. Em países de sistema confessional prevalece a religião, quando não, costumes próprios a determinada crença.

O Brasil que, até 1942, teve como conexão pessoal, a nacionalidade na Introdução ao Código Civil, de 1916, passou a acolher o domicílio e, à sua falta, a residência habitual da pessoa, tal como se encontra nas regras de Direito Internacional Privado da Lei de Introdução ao Código Civil (arts. $7^{\circ}$ a 19).

Dadas as dificuldades e aos problemas que surgiram com a dualidade dos princípios de nacionalidade e domicílio nas questões internacionais, ou melhor, nos relacionamentos interpessoais, o Instituto de Direito Internacional, em sessão realizada em 1987, baixou Resolução tendente a facilitar a interpretação para a comunidade internacional, visando harmonizar as regras de conflito em vigor nos diferentes Estados. A Resolução buscou alertar os Estados no sentido de não usar com exclusividade o princípio da nacionalidade e/ou do domicílio nas questões de jurisdição; bem como, de permitirem alternativas e opções aos interessados, particularmente em questões de família (casamentos, divórcio, etc.), quando os conflitos de leis fossem ocasionados por diferenças de nacionalidades e domicílios, de sorte a que se pudesse alvitrar soluções pelo domicílio comum, sem prevalecer uma nacionalidade sobre a outra, ou se não tivessem domicílio comum, que se pudesse optar pela nacionalidade comum.

As Resoluções do Instituto funcionam como uma soft law, ou seja, recomendações de tendência uniformizadora no enfoque de determinadas matérias. Daí ser ele também conhecido como UNIDROIT. Por vezes, examina projetos que, a longo prazo, podem resultar numa Convenção. 
Um exemplo, no Direito alemão, bem ilustra como países que sempre tiveram na nacionalidade o vínculo pessoal de conexão, introduziram modificações legislativas em vários assuntos, reafirmando, a cada passo, a competência não exclusiva de seus tribunais, mesmo em questões envolvendo cidadãos alemães e que tenham domicilio habitual na Alemanha. Refiro-me à nova Lei de Introdução ao Código Civil, com as últimas alterações de 25.07.1985 e suas "Disposições Transitórias" face a alterações introduzidas no Código Civil, Processual Civil, Lei das Nacionalidades, do Casamento, entre outras. Com todas as modificações lá realizadas evidenciam-se alternativas e opções de vínculos pessoais específicos, sendo certo que o art. 23 da Lei de Introdução ao Código Civil Alemão, ao tratar do "consentimento do filho e de uma pessoa com a qual a criança estiver ligada por laços familiares, quanto ao atestado de descendência, o nome, a legitimação ou a adoção como filho estão, além disso, subordinados ao direito do país do qual a criança é cidadã" (grifos nossos). ${ }^{3}$

Com estas colocações que fiz, no desejo de facilitar um melhor entendimento da Convenção de Haia de 1993 que estava examinando, é possível concluir-se que ela foi além das considerações quanto a nacionalidades e domicílios dos envolvidos em adoções transnacionais, consignando o fator de conexão na residência habitual do adotante e do adotando, fixando a competência das autoridades dos Estados de origem (do adotando) e de acolhida (do adotante). Tal posicionamento espancou as divergências que salientei quanto aos possíveis conflitos espaciais de leis e conflitos de autoridades.

Se se fizer uma análise histórica das Conferências de Haia de Direito Internacional Privado chega-se à conclusão de sua larga experiência adquirida ao longo dos anos e o sensível desejo de que a proteção de menores e a adoção internacional viessem a ter um tratamento mais uniforme, de sorte a poder contar com maior número de Estados que a subscrevessem.

Com efeito, em 1961, a Convenção sobre Proteção de Menores e Adoção Internacional trouxe em seu bojo a determinação da lei aplicável, a competência de autoridades e o reconhecimento de decisões estrangeiras a esse respeito, só sendo sufragada pela Áustria, Reino Unido e Suíça, vigorando em 1965, portanto, somente entre estes três Estados. Entretanto, os três signatários dessa

3. Consulte-se Rivista di Diritto Internazionale, 1987 p. 495 e ss.; ou Rivista di Diritto Internazionale Privato e Processuale, 1986 pp. 718 e ss. 
Convenção implementaram modificações legislativas posteriores sem se desvincularem dos compromissos convencionais.

A Áustria, em 1978, adotou normas especiais de Direito Internacional Privado em seu JPR Gesetz. ${ }^{4}$

Grã-Bretanha e Escócia, sempre preocupadas com a competência internacional, ignorando outros aspectos do Direito Internacional Privado, aplicam sempre a lex fori, acolhendo as três formas de adoção previstas naquela Convenção: as realizadas na conformidade de regras legais gerais, as que obedecem ao Adoption Act, de 1968, e a adoção provisória contemplada no Adoption Act, de 1958, para os não-domiciliados na Inglaterra e na Escócia e que não atribui direitos sucessórios, nem cidadania ao adotado. Este $A c t$, de 1958 foi parcialmente ab-rogado em 1960 e as adoções ordinárias ficaram consolidadas no Adoption Act, de 1976, após diversas emendas anteriores.

Com relação à Suíça, a Lei Federal de Direito Internacional Privado foi modificada em dezembro de 1987 , sendo que no art. 85 , ao cuidar da Tutela e Outras Medidas de Proteção, faz referência expressa à Convenção de Haia de 61/65, estendendo sua aplicação, por analogia, às pessoas que não tenham residência habitual em um dos Estados contratantes. ${ }^{5}$

Reporto-me, neste passo, a um parecer que exarei em 1978, a propósito da adoção de um menor, brasileiro, por escritura pública, no Brasil, comparecendo o adotante representado por procurador bastante. O fato já estava consumado quando a mãe biológica dessa criança pretendia incetar procedimentos judiciais, vez que o adotante falecera e o Tribunal de Tutela do Cantão de Zurich, nomeara tutor do menor, um cidadão suíço, solteiro, que não reunia condições para o exercício do munus. Tive a oportunidade de bem examinar à luz do Direito estrangeiro e nacional, as barreiras e percalços que a indigitada consulente teria de enfrentar. O parecer se acha publicado na Revista dos Tribunais, v. 518, dez, 78, pp. 46 a 52, esclarecendo que não se cogitou da Convenção de Haia de 61/65, inaplicável ao Brasil.

\footnotetext{
4. Consulte-se: Rivista di Diritto Internazionale e Processuale, 1981, pp. 801 e ss.

5. Consulte-se: Rivista di Diritto Internazionale e Processuale, 1989, pp. 196 e ss.
} 
5. Outros importantes aspectos da convenção sobre cooperação internacional e proteção de crianças e adolescentes em matéria de adoção internacional - entidades dedicadas à adoção.

Devo salientar a relevância dessa Convenção multilateral a que o Brasil se acha vinculado e o faço por motivos justos, humanos e humanitários, bem como porque se coaduna com o preceituado no Estatuto da Criança, especialmente no que concerne às condições para que se efetive a adoção: Estado de origem do adotando.

Lamentavelmente, razões sócio-econômicas, assimetrias existentes dentro do Brasil, ignorância de princípios de higiene e preservação da saúde em variados redutos nacionais, ausência de escolaridade, favorecimento à prostituição, à gravidez indesejada, ao uso e tráfico de estupefacientes têm contribuído para a marginalização de um percentual elevado de menores e adolescentes ampliando os índices de violência. A sociedade, de um modo geral, prefere rotulá-los de infratores, delinqüentes, esquecendo-se que são seres humanos, merecedores, pelo menos, de caridade cristã, sem assistencialismos, porém de atenção. É bem verdade que vários movimentos e organizações governamentais e não-governamentais vêm desenvolvendo esforços para redirecionar a vida destes menores. Umas, com êxito; outras, nem tanto.

Dispomos de lei especial que favorece às adoções e a colocação de menores em lares substitutos, quando deixados em abandono. Ocorre, porém, que as adoções pretendidas por nacionais, via de regra, perpetram discriminações.

Todavia, o estrangeiro que se dispõe a adotar menor em países que enfrentam dificuldades sócio-ecônomicas, é menos exigente e muitas vezes, aceita crianças com deficiências físicas e até mentais, pela possibilidade que vislumbram em lhe dar um atendimento melhor em seu país de origem.

Ora, com o objetivo transparente do âmbito de aplicação da Convenção de Cooperação Internacional em Matéria de Adoção, previsto no art. $1^{\circ}$. letras $a, b$ e $c$, ou seja: o interesse superior da criança, com respeito aos seus direitos fundamentais, assegurando-se essas garantias e o reconhecimento das adoções realizadas segundo a Convenção, previne-se o seqüestro, a venda e o tráfico de crianças transfronteiras.

Alie-se, ainda, que dos arts. $6^{\circ}$ a 13 , a Convenção estabeleceu que o Estados designarão uma Autoridade Central encarregada de dar cumprimento às obrigações impostas pela própria Convenção e que intermediará a aproximação com 
as autoridades públicas ou outros organismos credenciados, autorizados pelas autoridades competentes dos dois Estados envolvidos em uma adoção transnacional.

A esse respeito é conveniente lembrar-se que existem, em diversos países, agências especializadas em adoções, com nomenclaturas diferenciadas, com trabalho relevante na busca de pais para crianças abandonadas. Estas organizações contam com apoio de autoridades competentes em adoção, vez que são credenciadas, sérias, no mister a que se dedicam nos países onde estão sediadas. Para funcionarem em países outros, necessitam de autorização das autoridades locais, fornecendo-lhes relatórios das atividades que exercem.

A título de exemplo, elenco algumas: na Suiça, a Terre des Hommes, com sede em Lausanne, reconhecida por lei em 01.04.1973. Sem preocupações de ordem política, social ou confessional, realiza serviços especializados para adoção de crianças estrangeiras, em qualquer parte do mundo, prestando auxílio, in loco, para crianças desvalidas e infelizes.

Outra, com sede em Dakota do Norte, nos EUA, é uma entidade religiosa evangélica, que consegue tratamento gratuito para crianças do Brasil, Índia e Colômbia. Refiro-me à SAME South American Missionary Evangelism, que manteve convênio com a FEBEM. Recebe donativos particulares, consegue tratamento gratuito em hospitais norte-americanos e atende a um pool de agências de adoção dos EUA. Note-se que as crianças brasileiras, que obtiveram tratamentos com a intermediação da $S A M E$, ficaram em casas de brasileiros, ou portugueses, no período.

Na Itália, com sede em Milão, posso citar o Centro Italiano per l'Adozione Internazionale - CIAI, que exerce atividades desde 1968 e a Associazione Amici dei Bambini Ai-Bi, criada em 1983, com base na Lei n. 184, de 1983, a que já me referi, que regula a adoção e guarda de menores na Itália e conta com prévia autorização dos ministros dos Negócios do Exterior e da Graça e da Justiça italianas. É associação católica; a $A i$-Bi é representada, no Brasil, pela ABRACI, fundada por voluntários, inspirada nas idéias do padre Mário Colombo (recentemente falecido e assessor do Papa), que trabalhou como missionário aqui e que era solicitado por famílias italianas desejosas de adotar crianças brasileiras em estado de abandono. A sede da ABRACI é em São Paulo, na Rua Jandáia, 218 e representa, também, a Adoptie Noor Nederland, com sede na Holanda.

Os Medicins $d u$ Monde realiza trabalho voluntário no Líbano e também no Brasil, para adoções internacionais. 
Tanto a Suécia, quanto a Noruega têm órgãos governamentais para controle de adoções internacionais que realizam em qualquer continente.

\section{Conclusão.}

A adoção internacional deve ser encarada com maior tranqüilidade, nesta fase histórica, sem nacionalismos e assistencialismos, num país que continua em grande dificuldade para resolver problemas, hoje, estruturais que parecem infindáveis com as indecisões políticas no enfrentamento vigoroso dos mesmos.

Caberá à sensibilidade dos Juizados da Infância e Adolescência, coadjuvados pelos órgãos governamentais e pelo trabalho que vem sendo realizado em alguns setores da sociedade brasileira, examinar com percuciência e compreensão a viabilidade de adoções internacionais, sem que se promova um entreguismo de brasileiros a países estrangeiros. Não é este o espírito que norteia o instituto.

Atendidas as exigências da lei especial brasileira e do direito interno convencional, em benefício de crianças deixadas em abandono e rejeitadas, por vezes, por adotantes nacionais, renascem cidadãos em outros países. Essas crianças encontrarão amor, respeito, família, desfrutando de melhores condições de vida, que lhes devolverão a auto-estima.

São Paulo, maio de 1997. 